\title{
Urban Scale, Environmental Pollution and Subjective Well-Being of Urban Residents
}

\author{
Weiwei Zhang \\ Jinan University, Guangzhou, China \\ Email: zhangww0306@126.com
}

How to cite this paper: Zhang, W.W. (2019) Urban Scale, Environmental Pollution and Subjective Well-Being of Urban Residents. Modern Economy, 10, 444-463. https://doi.org/10.4236/me.2019.102030

Received: January 18, 2019

Accepted: February 15, 2019

Published: February 18, 2019

Copyright $\odot 2019$ by author(s) and Scientific Research Publishing Inc. This work is licensed under the Creative Commons Attribution International License (CC BY 4.0).

http://creativecommons.org/licenses/by/4.0/

\section{(c) (i) Open Access}

\begin{abstract}
Based on the micro-data of China's household income survey and urban macro-data, this paper uses two-stage least squares (2SLS) to explore the impact of urban scale and environmental pollution on the subjective well-being of urban residents. The study found that there is a significant inverted U-shaped relationship between urban scale and subjective well-being of urban residents. Environmental pollution has a positive impact on the subjective well-being of urban residents. Due to the existence of urban scale thresholds, only 46 small cities such as Qingyuan, Jincheng, Shangqiu, Fuxin, Changde and Qujing are not sensitive to environmental pollution. For first-tier and second-tier cities, urban scale and subjective well-being of urban residents are significantly positive. U-type relationship, environmental pollution has a significant negative impact on residents' subjective well-being, but due to the "urban scale threshold" effect, urban residents in big cities such as Beijing and Chongqing are not sensitive to environmental pollution caused by urban expansion.
\end{abstract}

\section{Keywords}

Urban Residents, Subjective Well-Being, City Size, Environmental Pollution, Self-Impact

\section{Introduction}

Over the past 30 years of Reform and Opening up, China's urbanization process has been accelerating. By the end of 2018, China's urbanization rate has reached up $58.50 \%$, and there are already ten cities with a population of more than 10 million. The development of urbanization has achieved remarkable achievements all over the world, but the improvement of urbanization level is not the ultimate goal of urbanization; the urbanization process brings happiness to people, which is the fundamental purpose of urbanization. Under the back- 
ground of rapid urban development, whether the expansion of urban scale in China has improved the happiness of residents or not has become the focus of attention.

The top ten lists of national happiness cities published by "China Economic Life Survey (2016-2017)” are Chengdu, Hangzhou, Nanjing, Xi'an, Changchun, Changsha, Suzhou, Zhuhai, Beijing and Shanghai. Obviously, the cities with the highest level of happiness among urban residents are second-tier cities, with first-tier cities behind them, and the list not involved other underdeveloped cities. The results show that the subjective well-being of different levels of urban residents is very different. Compared with other cities, the first-tier and second-tier cities are happier, but the larger the city, the higher the happiness which is an obvious mistake. Compared with the first-tier cities, the second-tier cities are happier. This may be due to the "urban disease" caused by the rapid expansion of urban scale, environmental degradation, housing shortages, social crimes, etc. which has reduced the subjective well-being of urban residents to a certain extent. The positive effect brought about by the expansion of urban scale has been these negative effects are offset.

Is the negative effect of urban scale expansion really serious? Lu Ming et al. [1] believe that the positive and negative effects brought about by the expansion of urban scale should be used to judge whether urban scale expansion is ultimately conducive to the overall development of the city, but due to the negative effects of urban scale expansion, its positive effects are not fully understood and focused. Judging the impact of urban scale expansion on the subjective well-being of urban residents should also fully consider the positive and negative effects of urban scale expansion. However, few studies have been conducted in this literature. In order to make up for the shortcomings of the existing research, this paper will use the two-stage least squares method (2SLS) to explore the impact of city size on the subjective well-being of urban residents. This paper will start from two aspects of positive and negative effects, and study the internal mechanism of urban scale affecting residents' subjective well-being, introduce the interaction between urban scale and environmental pollution to test whether the city scale affects the subjective well-being of urban residents through environmental pollution, and explore the impact of urban scale and environmental pollution on cities of different levels.

The contribution of this paper lies in: First, because the impact of urban scale and environmental pollution on different levels of cities may be different, this paper divides the sample cities into two groups, first-tier and second-tier cities and other cities, and uses group regression to explore the scale of the city and environmental pollution. The influence of subjective well-being of urban residents in different levels of cities; Secondly, introduce the interaction items of urban scale and environmental pollution, confirming that environmental pollution is a major transmission channel for urban residents to influence the subjective well-being of urban residents; Thirdly, introducing the concept of "urbanscale threshold" has explained the different influences of environmental pollution 
on subjective well-being of urban residents of different scales. Fourth, most previous studies have neglected the possibility of endogenous problems between urban scale and subjective well-being. Therefore, this paper adopts two stages. The least squares method (2SLS) is used for estimation, in order to provide reference for the direction of urban development planning in China.

Next, the structure of this paper is as follows: The second part reviews the literature related to subjective well-being, the third part outlines the theoretical analysis framework of this paper, the fourth part explains the data sources, the definition of relevant variables and the model setting, the fifth part introduces the empirical analysis results, the sixth part reports the robustness test, and the seventh part summarizes the research findings and puts forward the policy recommendations.

\section{Literature Review}

The study of the relationship between urban scale and happiness, Chinese scholars originally studied the optimal city scale from the perspective of welfare. Xiao Wen et al. [2] modeled under the framework of new economic geography, explored the optimal city size from the perspective of externalities, and estimated the benefits. There is a significant inverted U-shaped relationship between the level and the size of the city. As the external economies of scale increase or the crowding effect decreases, the optimal city size also expands. Happiness is called utility in economics. So is the study of the optimal size of the city from the perspective of welfare equal to the study of the relationship between urban size and subjective well-being? Samuelson proposed the famous happiness formula: happiness $=$ utility/desire, desire is the goal to be achieved, which shows the subjectivity of happiness, different subjects have different subjective experiences of happiness, even the same individual in different situations the subjective experience is also different. Therefore, although subjective well-being is not completely equivalent to utility, subjective well-being and utility are highly correlated.

So, what is the connection between city size and subjective well-being? At present, there are few studies on the relationship between city size and subjective well-being at home and abroad. The results of Delken [3] show that the decline of urban scale does not affect the subjective well-being of residents, because people do not pay attention to urban changes, but also pay attention to urban employment opportunities and crime rates; Philip [4] believed that in New Zealand, the larger the city size and the higher the population density, the higher the subjective well-being of people; The study by Okulicz-Kozaryn [5] uses a polynomial survey weighted regression to show that when the size of the US city is too large, residents subjective well-being has declined significantly. It can be seen that the influence of the size of cities in different countries on the subjective well-being of residents is significantly different. So what impact does the size of the city have on the happiness of Chinese residents? With the rapid development 
of urbanization in China, there is also a small amount of literature in China that studies subjective well-being from the perspective of urban scale. Yuan Zheng et al. [6] used ordinary least squares (OLS) analysis, the results show that there is a significant "inverted U" relationship between city size and residents' subjective well-being; Qi Yidong et al. [7] based on the orderly Probit model, the survey data of China Comprehensive Social Survey (CGSS) in 2006 and 2008 are analyzed. It is considered that the expansion of city scale has a significant negative impact on residents' subjective well-being, and the negative effect on residents in the eastern region is significantly higher. Residents in the western region; Cai Jinghui et al. [8] used the instrumental variable method to explore the impact of urban size on the happiness of the floating population, and considered that the city size and the floating population showed a significant "positive U" relationship, and the income was the main transmission path of urban scale affecting the happiness of floating population.

The expansion of urban scale is accompanied by environmental problems, and a few literatures explore the impact of urban pollution on residents' subjective well-being. Huang Yongming et al. [9] used the ordered Probit model to regress the data of the China Comprehensive Social Survey (CGSS) in 2003 and 2004, the results show that the working environment and living environment have an important impact on residents' subjective well-being, the air pollution also significantly reduced the subjective well-being of residents; Li Mengjie [10] selected the orderly Probit model to explore the "absolute deprivation effect" and "relative deprivation effect" of environmental pollution on residents' subjective well-being, and believed that there is an environment pollution significantly reduces the "absolute deprivation effect" of residents' subjective well-being by affecting residents' physical health, quality of life and social activities, and the "relative deprivation effect" of lower-income groups taking greater welfare losses due to environmental pollution.

In summary, scholars have not studied much about the impact of urban scale and environmental pollution on residents' subjective well-being, the study of the subjective well-being of residents by urban scale needs further study. This paper will use two-stage least squares (2SLS) to explore the impact of urban scale and environmental pollution on the subjective well-being of urban residents, and introduce the interactive items of urban scale and environmental pollution to explore whether the urban scale affects the urban residents' subjective happiness through environmental pollution. Sense, and analyze the difference between the size of the city and the impact of the environment on different levels of cities.

\section{Theoretical Analysis Framework}

This paper analyzes the influence of urban scale on subjective well-being and draws on the idea of New Economic Geography. The influence of urban scale on the subjective well-being of urban residents is mainly reflected in the positive external effect, that is, the aggregation effect and the negative external effect, 
namely the crowding effect. Since people's subjective well-being is highly correlated with utility, based on the utility function theory, the subjective well-being of individual residents in a city scale can be represented by a utility function. Assume that the $\mathrm{u}$ representing the utility of individual residents, $x$ representing the size of the city, a representing the positive impact of the size of the city, $d$ representing the negative impact of the size of the city, and $z$ representing the other factors affecting the subjective well-being of urban residents, the individual utility function of urban residents can be expressed as: $u(a(x), d(x), z)$.

Using the utility function to guide the city scale $x$, the marginal effect of the positive impact of the city scale on the subjective well-being of urban residents is: $[\partial u(a(x), d(x), z) / \partial a(x)] *[\partial a(x) / \partial x]$, when it is greater than 0 , the expansion of urban scale will bring about a clustering effect and enhance the subjective well-being of urban residents. The most obvious advantages of big cities are mainly reflected in the perfect public services. Ma Liang [11] found that improving the quantity and quality of public services provided by the government can enhance residents' happiness. In addition, the expansion of the city scale will bring many other positive externalities, such as more complete production, finance, information, and technical services, forming a market of a centralized scale, and will be in technology, due to the concentration of industry and population. Knowledge, human capital and other aspects of the spillover effect will inevitably increase employment opportunities. Therefore, the agglomeration effect brought about by the expansion of urban scale may enhance the subjective well-being of urban residents.

Use the utility function to bias the city size $x$, the marginal effects of the negative impact of urban size on the subjective well-being of urban residents are: $[\partial u(a(x), d(x), z) / \partial d(x)] *[\partial d(x) / \partial x]$, when it is less than 0 , the expansion of urban scale will also bring crowding effect and reduce the subjective well-being of urban residents. The crowding effect caused by over-expansion of population may lead to "urban disease" problems such as environmental pollution, traffic congestion, rising house prices, and inconvenience to people's lives, thus affecting the subjective well-being of residents. Xie Yang et al. [12] found that PM2.5 pollution has a serious negative impact on the health of residents in the Beijing-Tianjin-Hebei region. Lin Jiang et al. [13] believe that the degree of housing price increase has a significant negative impact on residents' subjective well-being. Therefore, the crowding effect brought about by the expansion of urban scale may reduce the subjective well-being of urban residents.

Based on the above analysis, the total marginal utility of city size for subjective well-being of residents can be expressed as:

$$
\begin{aligned}
\partial u(a(x), d(x), z)) / \partial x= & {[\partial u(a(x), d(x), z) / \partial a(x)] *[\partial a(x) / \partial x] } \\
& +[\partial u(a(x), d(x), z) / \partial d(x)] *[\partial d(x) / \partial x]
\end{aligned}
$$

That is to say, the aggregation effect and crowding effect brought about by the expansion of urban scale should be the same within the city. Whether the urban 
expansion will ultimately improve the subjective well-being of urban residents depends on the total marginal utility. Therefore, the rise and fall of the subjective well-being of urban residents depends on which effect is greater; when the marginal utility of the aggregation effect is greater than the absolute value of the marginal utility of the crowding effect, the subjective well-being of the urban residents rises; when the marginal utility of the aggregation effect is less than the crowding when the marginal utility of the effect is absolute, the subjective well-being of urban residents declines. The above theoretical analysis can be represented by Figure 1. We believe that the current aggregate effect of the expansion of China's first-tier and second-tier cities is greater than the negative effects caused by the crowding effect. Although environmental pollution is not conducive to the health of residents, the adverse effects of the environment have declined due to the existence of aggregation effects, which is the reason that there still a large number of migrant workers willing to flow to big cities.

\section{Data and Model}

\section{Data Introduction}

1) Data source

The data used in this article has two sources. Individual microdata are from China Household Income Projects (CHIP). CHIP is mainly a survey project initiated by the China Institute of Income Distribution of Beijing Normal University. Since 1988, a total of 7 household surveys have been conducted. Due to the focus of each year's questionnaire and the size of the sample, the research focus is based on the survey data of the most recent year, 2013, is used as individual microdata. The survey covered 126 prefecture-level cities in 14 provinces (Beijing, Shanxi, Liaoning, Jiangsu, Anhui, Shandong, Henan, Hubei, Hunan, Guangdong, Chongqing, Sichuan, Yunnan, Gansu) in eastern, central and western China. The data content includes the personal status of household members, household disposable income, and subjective issues related to the quality of life, and is widely representative. This paper focuses on the impact of urban scale and environmental pollution on the subjective well-being of urban residents. Therefore, through the integration and screening of family data and individual data, this paper finally obtains 6017 valid samples of urban residents from 20098 urban individual samples. At the same time, in order to correspond with the micro data, the macro statistics of the sample city are selected from the 2014 China Urban Statistical Yearbook. Since the individual samples are urban residents, this paper selects the statistical data of "urban area" or "city district" for analysis.

2) Definition of subjective well-being, city size, environmental pollution and city-level division

a) Subjective well-being

Subjective well-being mainly refers to the emotional and cognitive overall evaluation of people's personal quality of life. It is a subjective concept and a stable indicator for assessing life satisfaction for a long period of time. This article 


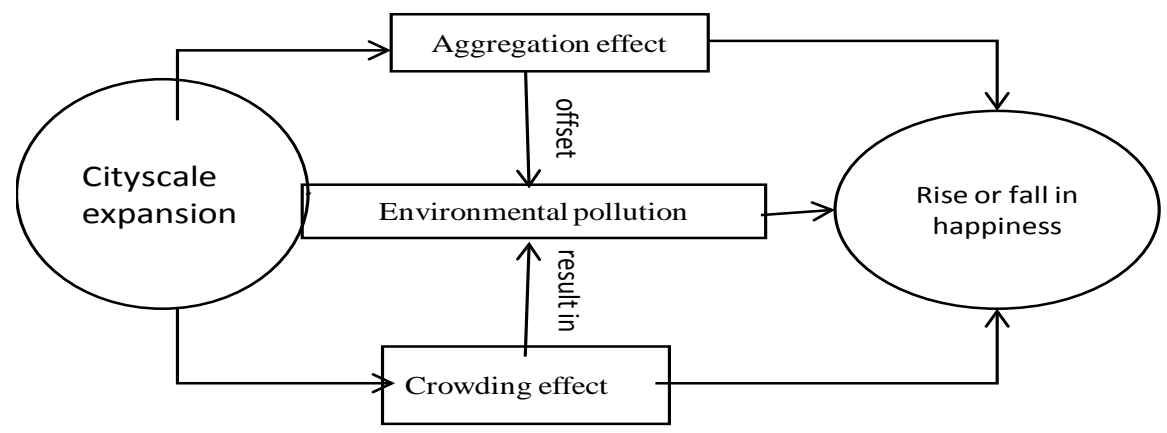

Figure 1. The impact of urban scale and environmental pollution on the subjective well-being of urban residents.

uses the survey to ask the interviewee to answer "Considering all aspects of life, do you feel happy"? The six answer options are "very happy, happy, average, not happy, very unhappy, don't know". This article deletes the sample of "don't know" and assigns 5, 4, 3, 2, and 1 to other options as indicators for measuring the subjective well-being of urban residents.

b) City size

For the measurement of urban scale indicators, in the past literature, Fu Hongchun et al. [14], Qi Yidong et al. (2014) used the total population of each city to measure the city size, Yuan Zheng et al. [15] selected cities the non-agricultural population represents the size of the city. It can be seen that the measurement indicators of the city scale have not yet been unified. This paper selects the number of employees at the end of the city's jurisdiction to measure the population. Because the working population refers to the total labor force who engages in certain social labor and obtains labor compensation or operating income, it can better reflect the characteristics of economic development speed and social development level of a city.

c) Environmental pollution

For the measurement of environmental pollution degree, in order to comprehensively consider the environmental impact of various types of urban pollutants, this paper selects four types of industrial wastewater discharge, industrial carbon dioxide emissions, industrial nitrogen dioxide emissions and industrial smoke (powder) dust emissions. Because the dimensions of the four environmental indicators are different and cannot be directly added, this paper uses the improved entropy method to construct a comprehensive indicator of environmental pollution, and determines the weight of each indicator so that it can objectively reflect the degree of urban environmental pollution. The specific indicator construction process is as follows:

Firstly, standardize the indicators: $X_{i j}^{*}=\left(X_{i j}-X_{\min (i)}\right) /\left(X_{\max (i)}-X_{\min (i)}\right)$, Among them, $X_{i j}^{*}$ standardized value for environmental pollutants, $i$ as an indicator of environmental pollutants, $j$ is the city, $X_{i j}$ as the initial value of the environmental pollutant indicator, $X_{\max (i)}$ and $X_{\min (i)}$ is the maximum and minimum values of the first environmental pollutant indicator. 
Among them, $X_{i j}^{*}$ is the standardized value of environmental pollutant indicators, $i$ is an indicator of environmental pollutants, $j$ is a city, $X_{i j}$ is the initial value of the environmental pollutant indicator, $X_{\max (i)}$ and $X_{\min (i)}$ are the maximum and minimum values of the first environmental pollutant indicator.

Next, calculate the proportion $Y_{i j}$ of the environmental pollutant index of the $i$ th item of $j$ city:

$$
Y_{i j}=X_{i j}^{*} / \sum_{j=1}^{m} X_{i j}^{*},\left(0<Y_{i j}<1\right)
$$

Finally, calculate the weight $W_{i}$ of the $i$-th indicator: entropy value $e_{i}=-K \sum_{j=1}^{m} Y_{i j} \ln Y_{i j}, K=1 / \ln n$, difference coefficient is $d_{i}=1-e_{i}$, the larger the difference coefficient, the stronger the importance of the $i$-th indicator. Therefore, the weight of the $i$-th indicator is $W_{i}=d_{i} / \sum_{j=1}^{m} d_{i}$.

Then the comprehensive environmental pollution index env $v_{j}$ of the constructed city $j$ is: $e n v_{j}=\sum Y_{i j} W_{i}$, the larger the environmental pollution comprehensive index env $v_{j}$, the higher the environmental pollution level of the city $j$.

d) City level division

Corresponding to the data used in this paper, the city-level classification of this paper uses the results of the first financial 2014 evaluation of China's urban level. According to the city's GDP, per capita income, top 500 entry, and the number of 211 colleges and universities, the First Financial Economics calculates the city's comprehensive business index for China's cities. The city is divided into one, two, three, four, and five by ranking. Six levels of six-tier cities. According to the results of this rating, this paper divides the city level of the sample city into first-tier and second-tier cities ${ }^{1}$ and other cities ${ }^{2}$ two categories. The first-tier and second tier cities include first-tier cities, second-tier developed cities, second-tier medium-developed cities, and second-tier cities with weaker development; other cities include third-, fourth-, fifth- and sixth-tier cities.

1) Descriptive statistical analysis

According to the main research content of this paper, the descriptive statistical information of the subjective well-being data of urban residents is reported in Table 1. It can be seen that the subjective well-being of urban residents in first-tier and second-tier cities is slightly lower than the overall average. The subjective well-being of urban residents in other cities is slightly higher than the overall average; The urban scales of first-tier and second-tier cities and other cities vary greatly. The average city size of first-tier and second-tier cities is 10.29 times that of other cities; the environmental conditions of first-tier and ${ }^{1}$ Firs-tier and second-tier including 21 cities: Beijing, Guangzhou, Shenzhen, Taiyuan, Shenyang, Dalian, Nanjing, Wuxi, Suzhou, Hefei, Jinan, Qingdao, Zibo, Yantai, Zhengzhou, Wuhan, Changsha, Foshan, Chongqing, Chengdu and Kunming.

${ }^{2}$ Other cities including 90 cities: including Anshan, Xuzhou and Yangzhou, etc. 
Table 1. Descriptive statistics.

\begin{tabular}{cccc}
\hline & Total & $\begin{array}{c}\text { First-Tier and } \\
\text { Second-Tier Cities }\end{array}$ & Other Cities \\
\hline \multirow{2}{*}{ Subjective well-being } & 3.743 & 3.738 & 3.748 \\
& $(6017)$ & $(2920)$ & $(3097)$ \\
City size & 0.596 & 2.222 & 0.216 \\
& $(111)$ & $(21)$ & $(90)$ \\
Environmental pollution & 0.009 & 0.0151 & 0.00759 \\
& $(111)$ & $(21)$ & $(90)$ \\
\hline
\end{tabular}

cities and other cities are also very different. The environmental pollution level of first-tier and second-tier cities is twice that of other cities. Therefore, the impact of city size and environmental pollution on different levels of cities is different. This paper will further test this conclusion.

2) Model setting

In this paper, we will focus on the impact of urban scale and environmental pollution on the subjective well-being of urban residents. Because the index of urban residents' subjective well-being is ranking variable, we should use the ordered Probit model to estimate it. However, this paper finds that the regression results of ordered Probit and OLS model are almost the same, and the marginal effect of OLS regression results is obvious. Therefore, this paper only reports the OLS regression results. The basic estimation equations in this paper are as follows:

$$
\begin{aligned}
\text { happiness }_{i j}= & \beta_{0}+\beta_{1} \text { cityscale }_{j}+\beta_{2} \text { cityscale }_{j} \wedge 2+\beta_{3} e n v_{j} \\
& +\beta_{4} \text { cityscale }_{j} * e n v_{j}+\beta_{4} M_{j}+\beta_{5} Z_{i j}+\varepsilon_{i j}
\end{aligned}
$$

Among them, the dependent variable happiness ${ }_{i j}$ is the subjective well-being of urban residents, while $i$ and $j$ represent the subjective well-being of urban residents and cities respectively, that is, to measure the subjective well-being of the $i$ th individual in $j$ city. $\beta_{1}$ is the estimation coefficient of urban scale. According to the previous literature, the relationship between urban scale and residents' subjective well-being is not simple linear. In this paper, we add a quadratic term of urban scale to explore the possible non-linear relationship between urban scale and residents' subjective well-being. The expansion of urban scale may lead to the deterioration of urban environment, and the urban scale may affect the subjective well-being of urban residents through the indirect influence of environmental pollution. Therefore, in order to investigate the interaction between urban scale and environmental pollution on the subjective well-being of urban residents, this paper also introduces the interaction between environmental and urban scale and environmental pollution as the main explanatory variables. In the basic estimation equation, $\beta_{2} \beta_{3}$ and $\beta_{4}$ are the estimation coefficients of the quadratic term of urban scale, environmental pollution, and the interaction term of urban scale and environmental pollution. The 
control variables include $M_{j}$ and $Z_{i j}$, in which $M_{j}$ is a macroeconomic variable at the urban level. This paper selects the average wage and GDP of urban employees to measure the impact of urban economic conditions on urban residents' subjective well-being. $Z_{i j}$ is an individual characteristic variable, which can be divided into three aspects:

1) Basic personal conditions of urban residents: mainly including gender, age and its square, education level, health status, marital status and whether they are members of the Communist Party or not. 2) Family economic status of urban residents: This paper chooses the relative income and total disposable income relative to the average living standard of the individual area as the measure index of household economic status. 3) Interpersonal trust: According to the interviewee's comment on "Do you think other people besides relatives and friends are trustworthy"? As a measure of interpersonal trust, the answer to this question reflects not only a person's sense of inner security to a certain extent, but also the social atmosphere to a certain extent. $\varepsilon_{i j}$ is a random perturbation term, assuming that it obeys the standard normal distribution. Detailed statistical characteristics of variables are shown in Table 2.

\section{Empirical Analysis}

\subsection{Empirical Analysis of Full Sample Regression}

1) Urban scale, environmental pollution and subjective well-being of urban residents

Although the control variables of urban macroeconomic factors and individual characteristics variables are set up in this paper, there are still unobservable factors affecting urban residents' subjective well-being, such as economic and personal characteristics. The errors of missing variables may still exist, leading to endogenous problems, and the results of OLS estimation are biased. On the other hand, large-scale cities usually have more employment opportunities, higher level of economic development and higher happiness of urban residents. This may also be the reason for attracting the migrant population, thus expanding the size of cities. Therefore, there is a two-way causal relationship between urban scale and subjective well-being of urban residents. If we do not solve the endogenous problem of urban scale, it will lead to biased and inconsistent estimation results. Therefore, it is necessary to use the instrumental variable method for analysis. The common method of urban scale instrumental variable is to select urban historical population data, because this variable affects the current urban scale, but there may also be a small correlation with subjective well-being. Considering the influence of the change of administrative divisions in China, the 1994 administrative divisions are the most consistent with the sample cities. In order to obtain accurate data and retain as many sample cities as possible, the non-agricultural population in urban areas in 1994 was chosen as a tool variable for the interaction between urban scale and its square sum, urban scale and environmental pollution, so as to avoid the endogenous relationship between urban scale and urban residents' subjective well-being. 
Table 2. Variable settings and related explanations.

\begin{tabular}{|c|c|c|c|c|c|}
\hline Variable type & Variable name & Variable definition & Samplesize & Average value & $\begin{array}{l}\text { Standard } \\
\text { deviation }\end{array}$ \\
\hline \multirow[t]{3}{*}{$\begin{array}{l}\text { Interpreted } \\
\text { variables }\end{array}$} & $\begin{array}{l}\text { Subjective } \\
\text { well-being }\end{array}$ & $\begin{array}{l}\text { Very unhappy }=1 \text {, Not very happy }=2 \text {, } \\
\text { commonly }=3 \text {, More happier }=4 \text {, Very happy }=5\end{array}$ & 6017 & 3.743 & 0.794 \\
\hline & City size & $\begin{array}{l}\text { End-of-term population of employees in cities } \\
\text { and municipal districts in } 2013 \text { (unit: millions) }\end{array}$ & 6017 & 2.225 & 3.010 \\
\hline & Square of city scale & $\begin{array}{l}\text { Quadratic end-of-term } \\
\text { number of employees in cities and municipal } \\
\text { districts in } 2013\end{array}$ & 6017 & 14.011 & 25.652 \\
\hline \multirow{2}{*}{$\begin{array}{l}\text { Main } \\
\text { explain } \\
\text { variable }\end{array}$} & $\begin{array}{l}\text { Environmental } \\
\text { pollution }\end{array}$ & Compound value of entropy method & 6017 & 0.0134 & 0.0144 \\
\hline & $\begin{array}{l}\text { Interaction between } \\
\text { urban scale and } \\
\text { environmental } \\
\text { pollution }\end{array}$ & $\begin{array}{l}\text { Multiplication of end-of-term number of } \\
\text { employees and environmental pollution } \\
\text { in municipal districts }\end{array}$ & 6017 & 0.0553 & 0.135 \\
\hline \multirow{7}{*}{$\begin{array}{l}\text { Macroeconomic } \\
\text { variables }\end{array}$} & $\begin{array}{l}\text { Average wages } \\
\text { of employees }\end{array}$ & $\begin{array}{l}\text { Average annual wages of on-the-job workers in } \\
\text { cities and municipal districts in } 2013 \\
\text { (unit: } 10,000 \text { yuan) }\end{array}$ & 6017 & 5.597 & 1.725 \\
\hline & $\begin{array}{l}\text { Gross regional } \\
\text { product }\end{array}$ & $\begin{array}{l}\text { Regional gross domestic product of cities and } \\
\text { municipalities in } 2013 \text { (unit: } 10 \text { billion yuan) }\end{array}$ & 6017 & 52.747 & 62.691 \\
\hline & Gender & Female $=0$, Male $=1$ & 6017 & 0.485 & 0.500 \\
\hline & Age & Age & 6017 & 49.088 & 13.408 \\
\hline & Age squared & Age quadratic & 6017 & 2589.42 & 1387.52 \\
\hline & Educational level & $\begin{array}{l}\text { Have never been to } \\
\text { School }=1 \text {, Primary school }=2 \text {, } \\
\text { Junior middle school }=3 \text {, } \\
\text { High school }=4 \text {, Specialty }=5\end{array}$ & 6017 & 3.970 & 1.281 \\
\hline & & Undergraduate college $=6$, Graduate student $=7$ & & & \\
\hline \multirow{6}{*}{$\begin{array}{l}\text { Personal } \\
\text { characteristic } \\
\text { variables }\end{array}$} & Health condition & $\begin{array}{l}\text { Very bad }=1, \text { Not good }=2, \\
\text { Commonly }=3, \text { Good }=4 \text {, Very good }=5\end{array}$ & 6017 & 3.886 & 0.856 \\
\hline & Are you married? & Unmarried $=0$, married $=1$ & 6017 & 0.885 & 0.319 \\
\hline & $\begin{array}{l}\text { Are they Party } \\
\text { members? }\end{array}$ & Is it a member of the Communist Party of China? & 6017 & 0.230 & 0.421 \\
\hline & Relative income & $\begin{array}{l}\text { Much higher }=1 \text {, Slightly } \\
\text { Higher }=2 \text {, Fair }=3 \text {, Slightly lower }=4 \text {, } \\
\text { Much lower }=5 \text {, Unclear }=6\end{array}$ & 6017 & 3.327 & 1.001 \\
\hline & $\begin{array}{l}\text { Total disposable } \\
\text { household income }\end{array}$ & $\begin{array}{l}\text { Total disposable income of households } \\
\text { in } 2013 \text { (unit: } 10,000 \text { yuan) }\end{array}$ & 6017 & 0.775 & 0.631 \\
\hline & Interpersonal trust & $\begin{array}{l}\text { Very credible }=1, \text { Not very credible }=2, \\
\text { Generally }=3 \text {, More credible }=4 \text {, Very } \\
\text { credible }=5, \text { Not clear }=6\end{array}$ & 6017 & 3.235 & 1.082 \\
\hline
\end{tabular}

In order to investigate the validity of tool variables, this paper carries out weak tool variables test and redundancy test. In the first stage of regression, the F statistic values of urban scale, square of urban scale and interaction between urban scale and environmental pollution are 6345.39, 11297.49 and 52412.13, which are far more than 10 , and the $\mathrm{P}$ values are all 0 . The original hypothesis of "the 
existence of weak instrumental variables" can be rejected; the P value of the redundancy test is 0 , indicating that the original hypothesis of excess instrumental variables is rejected at the level of $1 \%$. In summary, the tool variables used in this paper are effective.

OLS and 2SLS regression were performed on the whole sample. The regression results are shown in Table 3. OLS regression results show that there is a positive U-shaped relationship between urban size and subjective well-being in China, but the impact of urban size on subjective well-being is not significant. After introducing the instrumental variables, the 2SLS regression results show that the relationship between urban size and subjective well-being in China is inverted U-shaped, which further illustrates the endogenous problem in OLS model, leading to biased and inconsistent regression results. The results are contrary to the 2SLS regression model.

The impact of environmental pollution on the subjective well-being of urban residents is positive, that is, environmental pollution has a positive effect on the happiness of urban residents, which seems somewhat unreasonable. However, the symbol of the interaction between urban scale and environmental pollution is positive, indicating that there is a "urban scale threshold" for the subjective well-being of urban residents [16], that is, when the city is small, the subjective well-being of urban residents increases with the increase of environmental pollution, but when the population size reaches a certain level, the expansion of the urban scale will cause urban residents to become sensitive to environmental pollution, and the increase in environmental pollution will lead to a decline in subjective well-being of urban residents. According to the regression results of the model, the urban scale threshold for the positive impact of environmental pollution indicators on the subjective well-being of urban residents in the overall environmental carrying capacity of the city can be calculated: Happyness $/ \partial($ env $)=2.760-14.75 \times$ cityscale $=0$, the "urban scale threshold" for the expansion of urban scale and the negative impact of environmental pollution is 0.1871 million people. The cities with less than 0.1871 million have 46 cities including Qingyuan, Jincheng, Shangqiu, Fuxin, Changde and Qujing, etc. These cities are small cities, their economic level is not developed, and high-quality enterprises are less likely to lead to job shortages. The migration of high-quality enterprises often leads to environmental pollution. Residents of these cities may not be sensitive to environmental pollution. The positive impact of raising employment and income levels is greater than the negative impact of environmental pollution.

2) The influence of other factors on the subjective well-being of urban residents

In terms of urban macroeconomic factors, the average wage of workers has no significant impact on the subjective well-being of urban residents, while the GDP has a significant negative impact on the subjective well-being of urban residents. This may be due to the relatively large proportion of government, enterprises, etc. 
Table 3. Estimated results of influencing factors of subjective well-being in the whole sample.

\begin{tabular}{|c|c|c|}
\hline Variable name & OLS & 2SLS \\
\hline City size & $\begin{array}{l}-0.0460 \\
(-1.35)\end{array}$ & $\begin{array}{l}1.795^{\star *} \\
(1.90)\end{array}$ \\
\hline Square of city scale & $\begin{array}{c}0.00923^{* * *} \\
(3.17)\end{array}$ & $\begin{array}{c}-0.0775^{*} \\
(-1.74)\end{array}$ \\
\hline Environmental pollution & $\begin{array}{l}0.343 \\
(0.52)\end{array}$ & $\begin{array}{l}2.760^{*} \\
(1.82)\end{array}$ \\
\hline Interaction between urban scale and environmental pollution & $\begin{array}{l}-0.291 \\
(-0.85)\end{array}$ & $\begin{array}{l}-14.75^{* *} \\
(-1.97)\end{array}$ \\
\hline $\begin{array}{l}\text { Average wages of } \\
\text { employees }\end{array}$ & $\begin{array}{c}0.0937^{\star * *} \\
(6.01)\end{array}$ & $\begin{array}{l}0.0455 \\
(1.42)\end{array}$ \\
\hline Gross regional product & $\begin{array}{c}-0.00319^{* * *} \\
(-4.12)\end{array}$ & $\begin{array}{c}-0.0432^{\star *} \\
(-2.09)\end{array}$ \\
\hline Gender & $\begin{array}{c}-0.105^{\star * *} \\
(-5.42)\end{array}$ & $\begin{array}{c}-0.0942^{\star * *} \\
(-3.71)\end{array}$ \\
\hline Age & $\begin{array}{c}-0.0267^{\star * *} \\
(-5.76)\end{array}$ & $\begin{array}{c}-0.0305^{* * *} \\
(-4.89)\end{array}$ \\
\hline Age squared & $\begin{array}{c}0.000307^{\star * *} \\
(6.89)\end{array}$ & $\begin{array}{c}0.000335^{\star * *} \\
(5.71)\end{array}$ \\
\hline Educational level & $\begin{array}{c}0.0190^{* *} \\
(2.09)\end{array}$ & $\begin{array}{c}0.0239^{* *} \\
(2.02)\end{array}$ \\
\hline Health condition & $\begin{array}{l}0.173^{\star * *} \\
(14.20)\end{array}$ & $\begin{array}{l}0.170^{\star * *} \\
(10.93)\end{array}$ \\
\hline Are you married? & $\begin{array}{c}0.300^{* * *} \\
(9.60)\end{array}$ & $\begin{array}{c}0.339^{* * *} \\
(7.61)\end{array}$ \\
\hline Are they Party members? & $\begin{array}{c}0.0874^{\star * *} \\
(3.53)\end{array}$ & $\begin{array}{c}0.0921^{* * *} \\
(2.91)\end{array}$ \\
\hline Relative income & $\begin{array}{l}-0.187^{* * *} \\
(-19.07)\end{array}$ & $\begin{array}{l}-0.178^{\star * *} \\
(-13.42)\end{array}$ \\
\hline Total disposable household income & $\begin{array}{c}0.0660^{\star * *} \\
(3.93)\end{array}$ & $\begin{array}{c}0.123^{* * *} \\
(3.35)\end{array}$ \\
\hline Interpersonal trust & $\begin{array}{c}0.0674^{* * *} \\
(7.73)\end{array}$ & $\begin{array}{c}0.0845^{\star * *} \\
(5.96)\end{array}$ \\
\hline Intercept term & $\begin{array}{l}3.256^{* * *} \\
(20.49)\end{array}$ & $\begin{array}{l}3.253^{* * *} \\
(16.06)\end{array}$ \\
\hline Adjusted R2 & 0.1573 & - \\
\hline Observation value & 6017 & 6017 \\
\hline
\end{tabular}

Note: ${ }^{* * *} \mathrm{P}<0.01,{ }^{* *} \mathrm{P}<0.05,{ }^{*} \mathrm{P}<0.1$, standard error in parentheses. 
in the GDP, and the small share of residents. Therefore, with the increase of the GDP, the happiness of residents will decrease.

In terms of the basic personal conditions of urban residents, the subjective well-being of urban women is significantly higher than that of men. This may be due to the fact that under the traditional concept of "male dominates, women dominate" in our country, men bear greater responsibilities and pressures in the family, so the subjective well-being of men is lower. There is a significant positive U-shaped relationship between age and subjective well-being; health status directly affects the subjective well-being of urban residents, the healthier the residents are, the higher their subjective well-being; marital status also affects the subjective well-being of urban residents, and the well-being of married urban residents is significantly higher than that of divorced, widowed and single urban residents. Party membership plays a positive role in improving the subjective well-being of urban residents. The main reason may be that urban residents with Party membership have higher social status and thus higher subjective well-being.

In terms of the economic status of urban households, the higher the disposable income and the relative income, the stronger the subjective well-being. It shows that income is still the main factor determining subjective well-being, and the higher the income, the better the ability to meet personal material needs.

In terms of interpersonal trust, interpersonal trust has the same effect on subjective well-being of urban residents at different city levels, and the more trust they have, the higher happiness they have. From a psychological point of view, the higher the degree of interpersonal trust, the more likely these groups are to be liked and respected by others, to establish harmonious and harmonious interpersonal relationships with others, and to respect the rights and values of others; these groups also have few problems of inner conflict and maladjustment, and are willing to open their minds to meet new friends and treat others and their thoughts with an inclusive attitude. Differences, good at dealing with interpersonal relationships; from the perspective of social ethos, social ethos is directly related to people's physical and mental health, the more harmonious the relationship between people, the happier people will be. Therefore, the higher the degree of interpersonal trust, the higher the subjective well-being of urban residents.

\subsection{An Empirical Analysis of Distinguishing Urban Level Regression}

Compared with other cities, the first-tier and second-tier cities have absolute advantages in economic development, resource conditions, geographical location and so on. For individuals living in the two types of cities, the evaluation criteria for happiness may also be different. Therefore, the impact of urban scale and environmental pollution on urban residents' subjective well-being may be different among different levels of cities. This paper carries out OLS and 2SLS regression for first-tier, second-tier and other cities respectively. Similarly, in 
order to check the validity of instrumental variables, this paper also carried out the test of weak instrumental variables and redundancy. The test results show that there is no problem of weak instrumental variables ${ }^{3}$. In order to save space, this paper only reports the regression results of the main explanatory variables, as shown in Table 4.

According to Table 4, OLS regression results show that there is a U-shaped relationship between urban size and subjective well-being, but one item is not significant. After considering the endogenous variables, this paper finds that the impact of city size and environmental pollution on different levels of cities varies greatly. Next, this paper will mainly analyze the 2SLS regression results. First-tier and second-tier cities have a positive U-shaped relationship with the subjective well-being of urban residents. According to the 2SLS regression coefficient, $($ Happyness $) /($ city scale $)=-0.803+2 \times 0.0531 \times$ city scale $=0$, we can find that: city scale $=7.5612$ million people (the number of employees at the end of the period), that is, when the city scale is larger than 7.5612 million people, the subjective well-being of urban residents will follow the city scale. According to the urban scale data of sample cities, this paper finds that only the number of employees in Chongqing exceeds its critical value at the end of the term, which indicates that most of the first-tier and second-tier cities are still in the stage of enlarging urban scale and decreasing happiness. Therefore, although the expansion of the first-tier and second-tier cities will bring a series of problems, such as traffic congestion, environmental deterioration, housing shortage, etc., it can improve the subjective well-being of urban residents in China if orderly guiding population flow, and expanding the scale of cities and giving full play to the agglomeration effect of big cities.

The urban residents' well-being in the first-tier and second-tier cities is very sensitive to the environmental pollution caused by the rapid development of cities. The environmental pollution indicators have a significant negative impact on the subjective well-being of the urban residents in the first-tier and second-tier cities. The bigger the environmental pollution indicators are, that is, the worse the environment, the lower the urban residents' well-being.

The symbols of interaction between urban scale and environmental pollution are positive. This paper argues that there exists a threshold of urban scale [16] for urban residents' objective well-being. That is, when the city is small, the subjective well-being of urban residents decreases with the increase of environmental pollution. Only when the population scale reaches a certain level, the negative impact of environmental pollution on the subjective well-being of urban residents will decrease. According to the regression results of the model, we can calculate the urban scale threshold of the positive impact of environmental pollution index on urban residents' subjective well-being under the existing ${ }^{3} 1$ ) Weak instrumental variable test: In the first-stage regression of first-tier and second-tier cities, the F-statistic values of the three instrumental variables are 664.95, 1418.98, and 1524.87, respectively. In the first-stage regression of other cities, three instrumental variables $\mathrm{F}$ statistics the values are 480.04, 240.84 and 1993.41, both of which are far greater than 10, and the P value is 0.2 ) Redundancy test: $\mathrm{P}$ values in first-tier and second-tier cities and other cities are all zero. 
Table 4. Estimated results of influencing factors of subjective well-being in grouped samples.

\begin{tabular}{ccccc}
\hline \multirow{2}{*}{ Variable name } & \multicolumn{2}{c}{ First-Tier and Second-Tier } & \multicolumn{2}{c}{ Other Cities } \\
\cline { 2 - 5 } Cities & OLS & 2 SLS & OLS & 2 SLS \\
\cline { 2 - 5 } City size & -0.0616 & $-0.803^{* *}$ & $0.849^{*}$ & $2.294^{* * *}$ \\
Square of city scale & $(-1.39)$ & $(-2.11)$ & $(1.94)$ & $(3.17)$ \\
& $0.0112^{* *}$ & $0.0531^{* *}$ & $-2.302^{* * *}$ & $-4.507^{* * *}$ \\
Environmental pollution & $(2.31)$ & $(2.44)$ & $(-4.48)$ & $(-4.32)$ \\
Interaction between urban scale & -6.683 & $-43.78^{* *}$ & 1.707 & 2.171 \\
and environmental pollution & $(-1.17)$ & $(-2.35)$ & $(0.56)$ & $(0.55)$ \\
& 0.0931 & $8.580^{* *}$ & -9.552 & -13.12 \\
Intercept term & $(0.09)$ & $(1.97)$ & $(-0.40)$ & $(-0.41)$ \\
control variable & $3.686^{* * *}$ & $3.841^{* * *}$ & $2.886^{* * *}$ & $2.754^{* * *}$ \\
Adjusted R2 & $(12.43)$ & $(11.77)$ & $(13.01)$ & $(11.90)$ \\
Observation value & Yes & Yes & Yes & Yes \\
& 0.1320 & - & 0.1935 & - \\
\hline & 2920 & 2920 & 3097 & 3097 \\
\hline
\end{tabular}

Note: ${ }^{* *} \mathrm{P}<0.01,{ }^{* *} \mathrm{P}<0.05,{ }^{\star} \mathrm{P}<0.1$, standard error in parentheses.

environmental carrying capacity of the first-tier and second-tier cities, i.e. $($ Happyness $) /(\mathrm{env})=-43.78+8.58 \times$ cityscale $=0$. It shows that the "urban scale threshold" [16] of the negative impact of environmental pollution caused by the expansion of urban scale in the first-tier and second-tier cities is 5.126 million. Considering the population size of each city, this paper finds that Beijing and Chongqing are the cities that exceed the urban scale threshold. The conclusion of this paper is in line with expectations and reality. Beijing and Chongqing are the cities of floating population gathering in the central, eastern and western regions respectively. They have absolute advantages in economy and resources. The positive effects of these advantages offset the negative effects of environmental pollution. The above empirical results are consistent with the above theoretical analysis.

The relationship between urban scale and subjective well-being of urban residents in other cities is "inverted U". According to the regression results, the largest urban scale of subjective well-being is 255,000 people. Hengyang City, Benxi City and Weihai City are within $5 \%$ of the scale. The interaction between environmental pollution and urban scale and environmental pollution has little effect on the subjective well-being of urban residents in other cities. According to the above descriptive statistical analysis, the environmental pollution index of the first-tier and second-tier cities is 0.0151 , and that of the other cities is 0.00759 . The latter is only $1 / 2$ of the former. The environment of other cities is better than that of the first-tier and second-tier cities. Urban residents are insen- 
sitive to environmental pollution, so it is reasonable that environmental factors have no significant impact on the subjective well-being of other urban residents.

\section{Robustness Check}

This paper chooses two ways to test the robustness of regression results. Considering that GMM estimation method can better solve the heteroscedasticity problem [17] than 2SLS method, as the first way of robustness test, this paper uses Sun Sanbai [18] et al. (2014) for reference, chooses GMM method to re-estimate the model, in order to test whether the regression results are consistent with the previous empirical results. The results of GMM estimation are shown in Table 5. Obviously, using GMM estimation method does not change the basic conclusions of this paper. This paper focuses on the first-tier and second-tier city size and subjective well-being is still a "positive U" relationship, and the higher the degree of environmental pollution, the lower the subjective well-being of urban residents. The symbols of interaction term between urban scale and environmental pollution are still positive, indicating the existence of urban scale threshold. The urban scale threshold value under GMM model is 5.126 million, which has no difference with the result calculated by 2SLS estimation method. The cities that exceed the urban scale threshold are still Beijing and Chongqing. The regression results of other cities are also consistent with the above empirical analysis results.

The second way is to use 2SLS and GMM methods to estimate subjective well-being after transforming it into binary variables to test the robustness of empirical results. Regarding "very happy, comparatively happy" as happiness, and "general, not very happy, very unhappy" as unhappiness, the estimated results are as shown in Table 6. Although the regression results of other cities after subjective well-being is transformed into binary variables are not significant, the regression results of the first-tier and second-tier cities that this paper focuses on are still consistent with the above empirical analysis results. The urban scale threshold estimated by 2SLS and GMM is 4.8583 million, which is different from the previous empirical analysis results, but it has not changed the conclusion that the cities exceeding The urban scale threshold are Beijing and Chongqing. To sum up, the empirical results of this paper are more robust.

\section{Conclusions and Suggestions}

This paper analyses the influence of urban scale and environment on the subjective well-being of urban residents, and finds that the relationship between urban scale and the subjective well-being of urban residents is "inverted $U$ " in general. Due to the existence of urban scale thresholds, only 46 small cities such as Qingyuan, Jincheng, Shangqiu, Fuxin, Changde and Qujing are not sensitive to the negative impact of environmental pollution due to the expansion of the city. For the first-tier and second-tier cities, the distribution of urban scale and urban residents' subjective well-being is "positive U", and the environment has a 
Table 5. Estimated results of influencing factors of subjective well-being in grouped samples (GMM robustness test).

\begin{tabular}{ccc}
\hline \multirow{2}{*}{ Variable name } & First-Tier and Second-Tier Cities & Other Cities \\
\cline { 2 - 3 } City size & GMM & GMM \\
\hline Square of City Scale & $-0.803^{* *}$ & $2.294^{* * *}$ \\
& $(-2.26)$ & $(2.95)$ \\
Environmental pollution & $0.0531^{* * *}$ & $-4.507^{* * *}$ \\
& $(2.64)$ & $(-4.20)$ \\
Interaction between urban scale and & $-43.78^{* *}$ & 2.171 \\
environmental pollution & $(-2.41)$ & $(0.47)$ \\
& $8.580^{* *}$ & -13.12 \\
Intercept term & $(2.04)$ & $(-0.36)$ \\
Control variable & $3.841^{* * *}$ & $2.754^{* * *}$ \\
Observation value & $(12.46)$ & $(11.97)$ \\
\hline
\end{tabular}

Note: ${ }^{* * *} \mathrm{P}<0.01,{ }^{* *} \mathrm{P}<0.05,{ }^{*} \mathrm{P}<0.1$, standard error in parentheses.

Table 6. Estimated results of influencing factors of subjective well-being in grouped samples (robustness test of binary variables).

\begin{tabular}{ccccc}
\hline \multirow{2}{*}{ Variable name } & \multicolumn{2}{c}{ First-Tier and Second-Tier Cities } & \multicolumn{2}{c}{ Other Cities } \\
\cline { 2 - 5 } & 2 SLS & GMM & 2 SLS & GMM \\
\hline City size & $-0.496^{* *}$ & $-0.496^{* *}$ & $0.738^{*}$ & $0.738^{*}$ \\
Square of City Scale & $(-2.10)$ & $(-2.23)$ & $(1.67)$ & $(1.66)$ \\
& $0.0307^{* *}$ & $0.0307^{* *}$ & $-2.020^{* * *}$ & $-2.020^{* * *}$ \\
Environmental pollution & $(2.28)$ & $(2.45)$ & $(-3.17)$ & $(-3.02)$ \\
Interaction between urban scale & $-28.46^{* *}$ & $-28.46^{* *}$ & -1.478 & -1.478 \\
and environmental pollution & $(-2.47)$ & $(-2.52)$ & $(-0.61)$ & $(-0.60)$ \\
& $5.858^{* *}$ & $5.858^{* *}$ & 16.78 & 16.78 \\
Intercept term & $(2.17)$ & $(2.23)$ & $(0.86)$ & $(0.84)$ \\
Control variable & $0.731^{* * *}$ & $0.731^{* * *}$ & $0.249^{*}$ & $0.249^{*}$ \\
Observation value & $(3.62)$ & $(3.66)$ & $(1.77)$ & $(1.77)$ \\
& Yes & Yes & Yes & Yes \\
\hline
\end{tabular}

Note: ${ }^{\star * \star} \mathrm{P}<0.01,{ }^{* \star} \mathrm{P}<0.05,{ }^{\star} \mathrm{P}<0.1$, standard error in parentheses.

significant negative impact on subjective well-being. Because of the "threshold of city size" effect, the negative impact of environmental pollution in Beijing and Chongqing is decreasing with the expansion of city size. In addition, this paper also finds that the stronger interpersonal trust, the higher subjective well-being 
of urban residents. The conclusion of this study has certain policy implications. Based on the research results, this paper puts forward the following suggestions on improving the subjective well-being of urban residents:

Firstly, the expansion of urban scale brings about the problem of "urban disease", but it is a problem that must be faced and solved in the process of urbanization in China. Taking Beijing as an example, the construction of Xiongan New District's capital deputy center to evacuate Beijing's non-capital functions may be an effective way to control urban diseases. In addition, we should guide the population flow in an orderly way, expand the scale of cities, give full play to the agglomeration effect of big cities, and promote the construction of "big city clusters" in China.

Secondly, most of the first-tier and second-tier urban residents will reduce their happiness because of environmental pollution. On the contrary, in Beijing, Chongqing and other cities, environmental pollution will enhance the happiness of urban residents, but this does not mean that environmental degradation is the way to enhance the subjective well-being of urban residents. It can only be said that the positive effect of the current expansion of the scale of these cities is greater than that negative effects of environmental pollution. Therefore, in the long run, a reasonable and feasible urban development plan should be formulated, based on the overall environmental capacity and resource carrying capacity of the city, and from the regional perspective, coordinate the coordinated development of urban and rural areas; adjust the urban economic structure, change the mode of economic growth and develop circular economy; deepen the comprehensive management of urban environment, improve the sustainable development capacity of urban ecology and build an environmentally friendly city.

Third, the overall social environment is related to people's happiness, and social atmosphere is the reflection of the overall social environment; good social atmosphere will invisibly improve people's subjective well-being. The controversy over the issue of "old people falling down and failing to help" reflects the crisis of trust between people, in essence, reflects the social atmosphere, and is a kind of anxiety about social integrity. Therefore, the government should guide a good social atmosphere, promote and maintain a good social atmosphere, and provide the people with a harmonious, fair and warm social environment as a whole.

\section{Conflicts of Interest}

The author declares no conflicts of interest regarding the publication of this paper.

\section{References}

[1] Lu, M., Gao, H. and Zuo, T.H. (2012) Urban Scale and Inclusive Employment. China Social Science, 10, 47-66.

[2] Xiao, W. and Wang, P. (2011) External Economies of Scale, Crowding Effects and 
Urban Development: A New Economic Geography Urban Model. Journal of Zhejiang University (Humanities and Social Sciences Edition), 41, 94-105.

[3] Delken, E. (2008) Happiness in Shrinking Cities in Germany. Journal of Happiness Studies, 9, 213-218. https://doi.org/10.1007/s10902-007-9046-5

[4] Morrison, P.S. (2011) Local Expressions of Subjective Well-Being: The New Zealand Experience. Regional Studies, 45, 1039-1058. https://doi.org/10.1080/00343401003792476

[5] Okulicz-Kozaryn, A. (2016) Unhappy Metropolis. Cities.

[6] Yuan, Z., Zheng, Y. and Han, Q. (2012) The Relationship between Urban Scale and Residents' Well-Being. Urban Issues, 5, 29-33.

[7] Tan, Y.D., Zhang, X.F. and Man, Q. (2014) Urban Size and Subjective Well-Being of Residents: Empirical Evidence from CGSS. Finance and Trade Research, 25, 11-17.

[8] Cai, J.H., Ren, B. and Huang, X.N. (2016) The Influence of City Size on the Well-Being of Floating Population: Empirical Evidence from RUMIC (2009). Journal of Guizhou University of Finance and Economics, 1, 89-99.

[9] Huang, Y.M. and He, L.Y. (2013) Urbanization, Environmental Pollution and Subjective Well-Being of Residents-Empirical Evidence from China. Soft Science of China, 12, 82-93.

[10] Li, M.J. (2015) Environmental Pollution, Government Regulation and Happiness of Residents: Empirical Analysis Based on CGSS (2008) Microsurvey Data. Contemporary Economic Science, 5, 59-68.

[11] Ma, L. (2013) Public Service Performance and Citizen Well-Being: An Empirical Study of Prefectural Cities in China. China Administration, 2, 104-109.

[12] Sun, J.W., Li, S.S. and Zhang, H.J. (2015) "Urban Disease" on the Loss of Urban Economic Efficiency: Based on the Study of 285 Prefecture-Level Cities in China. Economic and Management Research, 36, 54-62.

[13] Xie, Y., Dai, H.C., Hua, G.D.Y. and Zeng, J.L.Y. (2016) PM_(2.5) Pollution's Impact on Population Health and Economic Impact in Beijing, Tianjin and Hebei. Population, Resources and Environment of China, 26, 19-27.

[14] Lin, J., Zhou, S.J. and Wei, W.Q. (2012) Urban Housing Prices, Housing Property Rights and Subjective Well-Being. Finance and Trade Economy, 5, 114-120.

[15] Fu, H.C., Jin, L. and Jin, L. (2016) The Optimal Urban Size under the Happiness Framework. Urban Issues, 2, 14-24.

[16] Wang, J. and Chen, H. (2016) The Impact of Transportation Facilities and Population Concentration Density on Urban Productivity: An Analysis Based on Panel Data of Prefecture-Level Cities in China. Urban Issues, 11, 53-60.

[17] Zhang, W.D. (2010) Study on the Theoretical Essence and Method Extension of GMM by Generalized Moment Method. Southwest University of Finance and Economics, Chengdu.

[18] Sun, S.B., Huang, W., Hong, J.J. and Wang, C.H. (2014) Urban Scale, Happiness and Migration Space Optimization. Economic Research, 49, 97-111. 